\title{
RESIDENTES, PRECEPTORES E TUTORES: CONSTRUÇÃO POLISSÊMICA DE SENTIDOS
}

\author{
Residents, preceptors and mentors: polisemyc construction of its meanings
}

Jackeline Lourenço Aristides - UNLP/Brasil

\begin{abstract}
RESUMO: Durante o exercício da metodologia ativa em uma Pós em Preceptoria do SUS tivemos como questões de aprendizagem: o perfil de competência do residente, preceptor e tutor. Frequentemente vemos conceituações diferentes para esses atores. Vamos fazer uma aproximação com esses termos e como refletimos essas atuações em nossas Residências Multiprofissionais. Como metodologia de pesquisa procedemos à busca documental na Base de Dados da Bireme e utilizamos como palavras-chave: "Papel do Preceptor", "Papel do Tutor", "Papel do residente", "Preceptoria", "Tutoria". Nessa seleção encontramos oito artigos dos últimos dez anos, além das portarias interministeriais. Notamos que as residências do município de Apucarana não estão alinhadas com as competências dos preceptores e tutores previstos na Portaria $\mathrm{N}^{\circ}$ $1.111 / \mathrm{GM}$ de 5 de julho de 2001, porém essa "confusão" não ocorre só em nossos programas, mas também em outras residências. Definir um perfil único de competência dos sujeitos envolvidos no processo da residência é impossível, pois cada programa tem sua historicidade e suas singularidades. Mais do que chegar a algum lugar, o que importa e nos motiva verdadeiramente é o percurso da viagem: "procurar apaixonadamente um lugar ainda é mais gratificante que achá-lo2". O papel do residente é o mesmo dos demais profissionais do SUS, o compromisso ético com a população, e a proposição de uma atuação pensada e ativada na mudança de modelo assistencial. Graças a essa busca, conseguimos nos instrumentalizar mais, e propusemos um encontro entre todos esses atores para atualizarmos esse debate.
\end{abstract}

Palavras-chave: Construção de sentidos. Estudante Residente. Tutor.

ABSTRACT: During an active methodology exercise in a post-graduation course in Preceptorship of the Brazilian Universal Healthcare System (SUS), there were questions about the competency profile of the nurse resident, preceptor, and mentor. Frequently, different concepts about these roles are seen. Let's get familiar with these terms and with how these concepts are reflected upon in our Multi-professional Residency program. As research methodology, the key-words: "Preceptor role", "Mentor role", "resident role", "preceptorship", "mentorship", were searched at Bireme database. Eight scientific articles were found in the past ten years using this search selection. We found that the residency program in the city of Apucarana is not compliant to the preceptors and mentors competencies stipulated by ORDINANCE \# 1.111/GM JULY 5TH 2005, but this "misunderstanding" doesn't happen only in our program, but also in other residency programs. It is impossible to define a specific profile for the competencies of the subjects involved in the residency program. Each program has its own history and singularities. Suggests that the journey is more important than reaching the destination: "passionately seeking a place is more gratifying than finding it." The resident's role is

Educação, Psicologia e Interfaces, Volume 3, Número 2, p. 184-195, Maio/Agosto, 2019. 
the same as every other SUS professional: to have an ethical commitment to the population, and the proposition of a conscious practice that enables a change in model of care. Thanks to this research, we were able to be better equipped, and we proposed a meeting with all residents, preceptors and mentors to discuss and debate the subject.

Keywords: polysemies. Residents. Mentor.

\section{INTRODUÇÃO}

Durante uma Pós em Preceptoria do SUS, mais precisamente no grupo diversidade fizemos a dinâmica da "dramatização" da atuação do residente, e como questões de aprendizagem surgiram questionamentos quanto ao perfil de competência do residente, preceptor e tutor e daí fomos para o estudo autodirigido. Durante o estudo autodirigido trouxemos as competências dos residentes, tutores e preceptores, porém, durante a discussão tivemos contato com outras literaturas de outros colegas e nos interessamos mais pelo assunto. Até porque essas são algumas das indagações que constantemente os preceptores nos trazem.

Para além disso, nosso interesse por esse tema foi despertado também durante os encontros entre os alunos dessa pós, onde víamos constantemente discussões acaloradas acerca do papel do preceptor, e que não estaria claro para os mesmos as competências desse ator.

Frequente vemos conceituações diferentes, dependendo do contexto em que as residências e graduações se encontram, com relação ao termo tutor e preceptor e suas competências. Sendo assim, o objetivo geral dessa reflexão é o de fazer uma aproximação com esses conceitos encontrados na Base de Dados, e o objetivo específico é o de promover uma reflexão de como os conceitos encontrados em nossa busca documental se alinha com nossa Residência Multiprofissional em Saúde Mental do município de Apucarana.

A justificativa para essa pesquisa se deve às confusões que existem nas conceituações destes termos, e a abrangência prática que eles podem ter. A relevância se coloca porque são poucos os estudos acerca da sistematização desses conceitos, e dos papéis para cada um deles.

Como metodologia de pesquisa procedemos à Revisão Bibliográfica na Base de Dados da Scielo Brasil, e utilizamos como palavras-chave: "Papel do Preceptor", "Papel 
do Tutor", "Papel do residente", "Preceptoria", "Tutoria”. Nessa seleção encontramos nove artigos, além das portarias interministeriais a saber: Jesus e Araujo (2011), Botti et al. (2006), Lima (2005), Silva et al. (2015), Bellodi (2003), Parente (2008), Melo Queluci e Gouvêa (2014), Steinbach (2015) e Silva (2013).

\section{RESULTADOS E DISCUSSÃO}

Apesar dos programas de Residência Multiprofissional existirem há mais de dez anos, ainda temos escassez de estudos acerca das competências dos residentes, tutores e preceptores. $\mathrm{Na}$ área de saúde mental apenas um estudo problematizou o papel do preceptor.

Acrescido disso Jesus e Araujo (2011) citam o documento intitulado "Residência Multiprofissional em Saúde: experiências, avanços e desafios do Ministério da Saúde que destacam alguns desafios para o processo de ensino-aprendizagem multiprofissional em contextos concretos do Sistema Único de Saúde (SUS): falta de diálogo entre futuros preceptores e tutores; falta de preparação para o trabalho coletivo, inclusive para a produção de conhecimento a partir de pesquisas sobre as temáticas relevantes ao contexto de prática-aprendizagem; falta de professores com perfil e disponibilidade para a tutoria (BRASIL, 2006, p.67).

Para entendermos tudo isso, vamos contextualizar a história das Residências Multiprofissionais. O Ministério da Saúde (MS) vem apoiando Residências Multiprofissionais em Saúde (RMS) desde 2002, por meio do projeto ReforSUS. O estabelecimento de financiamento regular para os Programas de Residências Multiprofissionais de Saúde no Brasil e o investimento na sua potencialidade pedagógica e política, tem por objetivo possibilitar tanto a formação de profissionais quanto contribuir com a mudança do desenho tecnoassistencial do Sistema Único de Saúde (SUS). A promulgação da Lei $\mathrm{n}^{\circ} 11.129$, de 30 de junho de 2005, que criou a Residência em Área profissional da Saúde e instituiu a Comissão Nacional de Residência Multiprofissional em Saúde (CNRMS), deu início ao processo de regulamentação da RMS. O MS, cumprindo o seu papel de gestor federal, elaborou, por meio do Departamento de Gestão da Educação na Saúde (Deges/ SGTES), as portarias que regulamentam a lei e subsidiam o financiamento das RMS, a saber: Portaria $\mathrm{n}^{\circ}$ 
1.111, de 5 de julho de 2005, Portaria $n^{\circ} 1.143$, de 7 de julho de 2005 e Portaria Interministerial no 2.117 de 3 de novembro de 2005 (BRASIL, 2011).

Segundo Pitkin (2006), como estamos falando de um país periférico, onde muitas palavras aqui utilizadas são resultados de traduções, devemos, antes, recordar que as palavras e o mundo andam juntos, mas não em correlação direta. Conforme Lima (2005, p.372), a concepção dialógica de competência trabalha com o desenvolvimento de capacidades ou atributos (cognitivos, psicomotores e afetivos) que, combinados, conformam distintas maneiras de realizar, com sucesso, as ações essenciais e características de uma determinada prática profissional. Assim, diferentes combinações podem responder aos padrões de excelência que regem essa prática profissional, permitindo que as pessoas desenvolvam um estilo próprio, adequado e eficaz para enfrentar situações profissionais familiares ou não familiares.

A Portaria $\mathrm{N}^{\mathrm{o}}$ 1.111/GM de 5 de julho de 2005 fala que a Residência Multiprofissional em Saúde deve contribuir para a formação de profissionais de saúde com perfil adequado às necessidades e políticas de saúde do País. Bem como sensibilizar e preparar estudantes e profissionais de saúde para o adequado enfrentamento das diferentes realidades de vida e de saúde da população brasileira em todo o território nacional. Assim, não há especificamente um papel bem definido para o residente, porém consideramos que este papel deve assimilar como relatado acima uma adequação de cada realidade.

O trabalho de Jesus e Araujo (2011, p.77) pontua elementos importantes para entendermos o universo dos residentes, os conflitos inerentes ao relacionamento com outros atores e os desafios da atuação em processos de trabalho engessados: "A participação dos residentes nos espaços de aprendizagem institucionais apresentados, particularmente no Grupo de Cidadania, demonstrou-se bem promissora para $\mathrm{o}$ desenvolvimento do processo de politização, embora seja importante ratificar que os espaços como as reuniões técnicas não mereçam a qualificação de promissora para a politização em relação aos demais, uma vez que, nesses momentos, a participação dos residentes era menos incentivada e, por vezes, limitada. Nas entrevistas realizadas com as residentes percebeu-se que elas tinham consciência da baixa receptividade de alguns profissionais em relação às suas opiniões, o que sugere um papel coadjuvante ou menos protagonista do que tinham no grupo de cidadania, por exemplo. Nessa mesma direção, 
pode-se afirmar que existia mais liberdade para a politização dos residentes nos espaços com concentração de usuários do que com a concentração de profissionais de saúde. Os sentidos e significados construídos pelas residentes em relação ao desenvolvimento de suas atividades e ao processo de organização do trabalho alicerçam a noção de que a politização pode ser entendida como tendência educativa com os princípios e diretrizes do SUS, e, particularmente, com a Reforma Psiquiátrica. No entanto, é preciso que o desenvolvimento de habilidades como a negociação, mediação e tolerância cause impacto nas relações entre os profissionais de saúde e destes com usuários e residentes, e que essas habilidades sejam elementos impulsionadores para o enfrentamento da cultura manicomial.

Ainda com estes autores, é fundamental ressaltar, que, do ponto de vista teórico, o processo de politização como imagem objetiva deve se distanciar do desejo manicomial. Do ponto de vista empírico, exigirá vigilância contínua para não sucumbir a tal desejo. As residentes tem a exata noção de que precisam vencer os obstáculos para que possam manter uma nova forma de cuidar, mesmo que, em alguns momentos tenham se calado ou recuado antes aos conflitos descritos aqui.

Em outro estudo de Silva et al. (2015) o programa de Residência Multiprofissional em Saúde foi compreendido como uma oportunidade significativa de aprendizado e contato com profissionais de diferentes áreas, permitindo assim que os residentes assumam uma nova conduta na prática profissional, onde a assistência aos usuários adquire um caráter mais humanizado e abrangente, através do compartilhamento efetivo dos conhecimentos específicos de cada área e a participação nas atividades de saúde.

Apontamos esses estudos aqui porque não há um perfil de competência específico para os residentes, mas, as percepções que os mesmos tem sobre a residência ajuda na construção do perfil aproximado do residente.

Percebemos que os desafios apresentados pelos autores acima sejam os nossos também em termos da pouca politização dos profissionais pela defesa da Reforma Psiquiátrica, e que esta instrumentalização seja conseguida somente nas tutorias e nos encontros dos usuários. Infelizmente, nem todos os preceptores tiveram suas formações profissionais transversalizadas pelas discussões da Reforma Psiquiátrica. 
Parente (2008) pontua que a questão fundamental diz respeito às possibilidades, limites, desafios e ao cenário de trabalho no qual se encontram inseridos tutores e preceptores. Essa questão, não raro, angustiante ou no mínimo inquietante, contribuiu para identificarmos algumas importantes pistas que podem favorecer a qualificação do fazer destes profissionais. O uso da palavra pista é intencional e busca refletir a idéia de que não temos ainda uma certeza acerca das atribuições, dos limites e dos muitos desafios que pairam sobre a dinâmica de trabalho destes profissionais. Temos, sim, bons indicativos a partir da nossa experiência local e de outros indicativos colhidos em diferentes contextos. Portanto, o que apresentamos como pista sugere algo ainda em processo e que se manifesta multifacetadamente; talvez seja essa uma das razões das angústias e dos eventuais desencontros. A única certeza é que precisamos continuar procurando, examinando, discutindo e pactuando coletivamente os elementos referentes ao conteúdo das práticas de tutores e preceptores.

Segundo Brasil (2005), a Portaria No 1.111/GM de 5 de julho de 2005, traz as seguintes determinações para o exercício da preceptoria: função de supervisão docenteassistencial por área específica de atuação ou de especialidade profissional, dirigida aos profissionais de saúde com curso de graduação e mínimo de três anos de experiência em área de aperfeiçoamento ou especialidade ou titulação acadêmica de especialização ou de residência, que exerçam atividade de organização do processo de aprendizagem especializado e de orientação técnica aos profissionais ou estudantes, respectivamente em aperfeiçoamento ou especialização ou em estágio ou vivência de graduação ou de extensão;

Tutoria: função de supervisão docente-assistencial no campo de aprendizagens profissionais da área da saúde, exercida em campo, dirigida aos profissionais de saúde com curso de graduação e mínimo de três anos de atuação profissional, que exerçam papel de orientadores de referência para os profissionais ou estudantes, respectivamente, em aperfeiçoamento ou especialização ou em estágio ou vivência de graduação ou de extensão, devendo pertencer à equipe local de assistência e estar diariamente presente nos ambientes onde se desenvolvem as aprendizagens em serviço;

Para Parente (2008), essas indicações dos papéis pelo Ministério da Saúde situam-se no formalismo normativo advindo de uma determinação legal. Esta pista de inspiração normativa agrega algo importante que diz respeito a: primeiro, situar o 
campo de trabalho de tutores e preceptores no plano da educação; segundo, não separar a docência da assistência. Tutores e preceptores não são professores na concepção tradicional, operando assepticamente no interior de uma sala de aula. A sua práxis educativa está inexoravelmente comprometida com os processos de trabalho e conseqüentemente com sua transformação.

Ainda com este autor, tutores e preceptores mediam relações, facilitam a inserção nos territórios e criam um ambiente metodológico que potencializa a aprendizagem e o trabalho interdisciplinar.

No estudo de Melo, Queluci e Gouvêa, (2014) apontou que os preceptores possuem competência assistencial, porém falham no papel educativo de estimular os residentes ao desenvolvimento de habilidades para o desempenho de tais procedimentos. Não são capazes de estreitar a distância entre teoria e prática, ao contrário, parece aumentá-la. O tutor seria um agente fundamental para o controle de um dos principais fatores limitantes da preceptoria na percepção dos residentes: a falta de integração entre campo de prática e discussão teórica (MELO; QUELUCI; GOUVÊA, 2014).

De acordo com Steinbach (2015), os preceptores desenvolvem sua função convivendo com o sentimento de insegurança reportado à pouca capacitação, e com a falta de tempo para preceptorar devido às exigências impostas pelo mundo do trabalho. Perseveram e acreditam na preceptoria motivados pelo sentimento de gratidão por participar de uma formação de qualidade, oportunidade de renovar sua prática e o contato com o meio acadêmico. Seu estudo apontou a necessidade de formação dos preceptores, principalmente relativa aos saberes pedagógicos com base na prática reflexiva e à necessidade de equacionar o tempo de dedicação do preceptor ao mundo da escola e ao mundo do trabalho. Conforme Silva (2013, p.27-18),

O tutor/preceptor e o serviço para além de oferecerem suporte, devam apostar nos residentes, em sua capacidade de encontrar caminhos, brechas em meio às dificuldades e oferecerem sua parcela de contribuição para o andamento do trabalho, junto às equipes, aos usuários e nas intervenções possíveis no território [...], penso que seja importante apostar na capacidade criativa do residente quando este se confronta com situações desafiadoras. [...] isso, sem dúvida não é uma empreitada simples; é necessário que esses acolhedores sejam me parece, uma mistura de cientistas, arquitetos, artistas. Penso que nesta residência o tutor deva funcionar como síndico, zelador, arquiteto, artista, afim de que seus moradores provisórios possam sentir 
segurança, encontrar desafios estimulantes, certo conforto e se neste período sentirem-se, por alguma intercorrência em qualquer momento, "fora de casa", possam tê-la como referência e retornar, sendo bem acolhidos.

No estudo de Bellodi (2003) o tutor do curso de graduação em medicina da USP seria o de alguém que:

- Está disponível para discussões sobre as escolhas do dia-a-dia da faculdade, da futura especialidade e também para questões mais pessoais e individuais de cada aluno (orientador, conselheiro);

- Acompanha a trajetória de cada aluno e conhece os desafios surgidos durante o curso (pessoa próxima, referência dentro da faculdade, ponte entre o aluno e a graduação).

- Compartilha suas próprias histórias contando os obstáculos que encontrou ao longo do caminho e como superou os desafios (papel de modelo);

- Encoraja a assumir riscos e explorar novas oportunidades de aprendizagem (papel suportivo);

- Encoraja a refletir sobre a experiência e a dividir esses momentos chave com os colegas (papel reflexivo).

Importante pontuar que os tutores neste caso estão envolvidos com alunos de graduação, que demandariam mais atenção pela imaturidade supostamente.

Ainda com esta autora, o tutor da Faculdade de Medicina da USP é, na realidade, a partir do que foi concebido nas diretrizes do programa, um mentor. A adoção do termo Tutor ocorreu por duas razões: pela não familiaridade das pessoas em geral com o termo Mentor em nossa língua e cultura e, além disso, pelo fato de não ser possível uma versão do termo Mentoring para a língua portuguesa. Orientador, professor, conselheiro, padrinho, modelo, referência, amigo, parceiro, assessor: um tutor/mentor parece poder "usar vários chapéus", isto é, diferentes estilos e abordagens. As esferas de atuação dos diferentes papéis apresentados explicitaram principalmente ações amplas, direcionadas tanto à vida acadêmica quanto à vida pessoal. A aproximação com o aluno e o estabelecimento de vínculos mais estreitos apresentaram-se também como uma demanda também dos professores, os quais, claramente em suas falas, revelaram não somente o desejo de promover transformações, mas especialmente de ser alvo delas também. 
Neste estudo, Bellodi (2003) trouxe o aspecto do "paternalismo" na orientação do tutor/mentor, ora tracejando relações de gênero, já que boa parte dos candidatos ao cargo de tutores naquela instituição eram do sexo masculino, ora por que tinham um "papel mais autoritário, do clínico mais antigo" (palavras minhas).

Pedro Demo (2000 apud PARENTE, 2008) sugere que mais do que chegar a algum lugar, o que importa e nos motiva verdadeiramente é o percurso da viagem: "procurar apaixonadamente um lugar ainda é mais gratificante que achá-lo". Nesse sentido, acreditamos que jamais teremos (ou "queremos") respostas definitivas que silenciem nossas bem-aventuradas inquietações pedagógicas. Precisamos de pistas que apontem para rumos possíveis, tendo consciência ainda que nem sempre tais rumos sejam seguros. Mas isso não deve nos impedir de ir em frente, pois seguir em frente é a única alternativa razoável possível.

Segundo Parente (2008), a assertiva acima compreende um esforço para caracterizar a complexidade do ato de educar em função das inúmeras, dinâmicas e contraditórias características do sujeito que pretende operar o ato educativo, bem como, do sujeito - alvo deste ato. Ambos são sujeitos multideterminados, ou seja, produto da história, do meio social, da cultura, da biologia, da espiritualidade, da política, enfim, expressão permanente de imanência e transcendência que caracterizam este processo vivo de ensinar e aprender. Além da diversidade de contextos, meios e abordagens que atravessam o processo educativo, há ainda a condição, para se ter sucesso, de não se descuidar um só instante, sob pena de graves conseqüências; ou seja, educar é um ato contínuo. Não cessa. Não pode sofrer interrupções. Não cabe vacilação por parte de quem gere tal processo.

Com relação ao papel do residente, encontramos apenas um artigo, em que refere que esse deve ser o mesmo dos demais profissionais do SUS, o compromisso ético com a população, e a proposição de uma atuação pensada e ativada na mudança de modelo assistencial. Criativo nos momentos mais difíceis, como o que vivemos de desmonte da saúde pública em nosso país. Ou seja, há quase uma inexistência de trabalhos refletindo essa perspectiva.

\section{CONSIDERAÇÕES FINAIS}


Notamos que o município de Apucarana não está alinhado com as competências dos preceptores e tutores previstos na Portaria $\mathrm{N}^{\circ}$ 1.111/GM de 5 de julho de 2005, porém essa "confusão" não ocorre só em nossos programas, mas também em outras residências. Assim, o que temos enquanto tutor é na verdade preceptor para o Ministério da Saúde e vice versa.

Definir o perfil de competência dos sujeitos envolvidos no processo da residência não é das tarefas mais fáceis, pois, cada programa tem sua historicidade e suas singularidades, porém é certo que nem todos os atores estarão prontos para essa atuação logo de início, e é desejável que seja assim.

Ainda que as instrumentalizações sejam fornecidas permanentemente para todos, e que as trocas entre a teoria e prática aconteçam, alguns não desenvolverão as habilidades necessárias para a preceptoria, principalmente, por alguns motivos: falta de Plano de Carreiras e Salários, desmotivação por falta de condições de trabalho, pouco diálogo entre trabalhadores e gestores seriam alguns deles, ausência de um estímulo como carga horária protegida ou bolsa-auxílio. Outros não conseguirão porque para ser preceptor quanto para ser tutor há a necessidade de revisão de si o tempo todo e do outro, e que a perspectiva de uma construção de uma metodologia ativa, com o aluno sendo o centro, sempre na busca da crítica reflexiva não é tão fácil assim. Mesmo sabendo que todo profissional de saúde deveria ser educador por "natureza", isso não está tão óbvio na prática desses sujeitos.

Com estas considerações, apontamos que se não nos apropriarmos das relações do saber envolvidos no processo pedagógico entre residente-preceptor e residente-tutor, ficaremos estagnados, fadados ao fracasso, culpabilizando ou vitimizando, ou criando bodes expiatórios. Se não compreendermos que os residentes são sujeitos únicos, que aprendem sob circunstâncias específicas, em momento histórico específico, vamos acreditar que os residentes são vaidosos, rebeldes, apáticos, sem contextualizar o porquê desses acontecimentos, o quê não é o mesmo de vitimizá-los, mas serem sujeitos protagonistas. Ao não apreendermos todos esses fenômenos também adoecemos, negamos, ou nos alienamos. Todo esse processo pode ser aprendido, mas tem que ser mediatizado.

Os objetivos acerca da conceituação dos termos preceptor e tutor, bem como suas competências foram alcançados, sendo delimitadas algumas confusões semânticas, 
e a necessidade de contextualização histórica desses papéis. Nesta revisão bibliográfica ficou evidenciado que existe uma lacuna no que tange ao conceito de residente, bem como da sua atuação. Sendo assim, seria necessária a realização de outras pesquisas científicas com essa reflexão.

\section{REFERÊNCIAS BIBLIOGRÁFICAS}

BRASIL. Portaria No $1.111 / \mathrm{GM}$ de 5 de julho de 2005. Fixa normas para a implementação e a execução do Programa de Bolsas para a Educação pelo Trabalho. Disponível em https://www.unila.edu.br/sites/default/files/files/portaria_1111_05-072005_-_bolsas(1).pdf. Acesso em: 20 julho 2017

BRASIL. Residência multiprofissional em saúde: experiências, avanços e desafio s. Ministério da Saúde. Secretaria de Gestão do Trabalho e da Educação na Saúde. Departamento de Gestão da Educação em Saúde. Brasília: Ministério da Saúde, 2006. Disponível em < http://bvsms.saude.gov.br/bvs/publicacoes/residencia_multiprofissional.pdf $>$. Acesso em: 24 de junho de 2017

BELLODI, Patrícia Lacerda. O que é um tutor?: Representações do papel em um grupo de professores de medicina durante o processo de seleção. Revista da ABEM, v.27, n.3, p. 205-212, 2003. Disponível em <http://www2.fm.usp.br/tutores/pub205-212 lic/revista2.php>. Acesso em: 18 jun. 2017.

JESUS, Monica Lima; ARAUJO, Diego. Politização e formação em serviço: significados e sentidos atribuídos pelos residentes em uma residência multiprofissional em saúde mental na Bahia. Psicol. teor. prat., São Paulo, v.13, n.3, p. 67-80, dez. 2011. Disponível em $<$ http://pepsic.bvsalud.org/scielo.php?script=sci_arttext\&pid=S1516$36872011000300006 \& \operatorname{lng}=$ pt\&nrm=iso $>$. acessos em 29 jul. 2017.

MELO, Myllena Cândido; QUELUCI, Gisella de Carvalho; GOUVÊA, Mônica Villela; Preceptoria de enfermagem na residência multiprofissional em oncologia: um estudo descritivo. Online Brazilian Journal of Nursing, v.13, n.4, p.656-666, 2014. Disponível em < http://www.objnursing.uff.br/index.php/nursing/article/view/4567>. acessos em 18 jun. 2017

PITKIN, Hanna Fenichel. Representação: palavras, instituições e idéias. Lua Nova: 2006. In: BOTTI, Sergio Henrique Oliveira; REGO, Sérgio. Preceptor, Supervisor, Tutor e Mentor: quais são seus papéis? Rev. Bras. Educação Médica. v.32; n.3. Disponível em < http://www.scielo.br/scielo.php?script=sci_arttext\&pid=S010055022008000300011>. Acesso em 20 jun. 2017

PARENTE, José Reinaldo Feijão. Preceptoria e tutoria na Residência Multiprofissional em Saúde da Família. Sanare, Sobral, v.7, n. 2, jul./dez 2008. Disponível em < 
https://sanare.emnuvens.com.br/sanare/article/download/31/26> Acesso em 15 jun. 2017

SILVA, Laerte Antonio e. "Era uma casa muito engraçada" - Relato de experiência de um tutor na residência multiprofissional em saúde mental coletiva. Universidade Federal do Rio Grande do Sul. Faculdade de Educação- Faced. Curso de Especialização Práticas Pedagógicas em Serviços de Saúde. Porto Alegre, 2013. Disponível em <https://www.lume.ufrgs.br/bitstream/handle/10183/76065/000892619.pdf?sequence=1 $>$ Acesso em 15 jun. 2017

SILVA, Jaqueline Callegari et al.. Percepção dos residentes sobre sua atuação no programa de residência multiprofissional. Acta Paul Enferm. v. 28, ed. 2, 2015. Disponível em <http://www.scielo.br/pdf/ape/v28n2/1982-0194-ape-28-02-0132.pdf> Acesso em 30 jun. 2017

STEINBACH, Marina. A preceptoria na residência multiprofissional em saúde: saberes do ensino e do serviço. Dissertação (mestrado) - Universidade Federal de Santa Catarina, Centro de Ciências da Saúde, Programa de Pós-Graduação em Odontologia, Florianópolis, 2015. Disponível em <https://repositorio.ufsc.br/xmlui/handle/123456789/157306> Acesso em 15 jun. 2017

\section{Credenciais da autora}

ARISTIDES, Jackeline Lourenço. Tutora na Residência Multiprofissional em Saúde Mental da Autarquia Municipal de Saúde de Apucarana- Paraná, graduada em enfermagem (UEL), Mestre em Saúde Coletiva (UEL) e Doutoranda em Ciências da Educação (UNLP). E-mail: jackeline.aristides@gmail.com

Endereço para correspondência: Rua Miguel Simeão, n.69; Centro, CEP. 86800-260, Apucarana/Paraná. E-mail: jackeline.aristides@gmail.com

Como citar este artigo (Formato ABNT): ARISTIDES, Jackeline Lourenço. Residentes, preceptores e tutores: construção polissêmica de sentidos. Educação, Psicologia e Interfaces, v. 3, n.2, p. 184-195, 2019. DOI: https://doi.org/10.37444/issn2594-5343.v3i2.146

Recebido: 29/04/2019.

Aceito: 26/05/2019. 